DESENVOLVIMENTO
$\begin{aligned} & \text { DESEIO AMBIENTE } \\ & \text { E MEISTEMA }\end{aligned}$

\title{
Conhecimento ambiental: indagações sobre o novo campo
}

\section{Environmental Knowledge: Investigations on the New Field}

\author{
José Edmilson de SOUZA-LIMA ${ }^{1}$ \\ ${ }^{1}$ Doutor em Meio Ambiente e Desenvolvimento (UFPR). Pesquisador e docente do Mestrado em Direito do Centro Universitário Curitiba \\ (UNICURITIBA). E-mail: zecaed@hotmail.com
}

Artigo: Recebido em: 5 de junho de 2013; Versão final aceita em: 1 de novembro de 2013.

RESUMO

No contexto do debate socioambiental contemporâneo, o objetivo deste artigo é indagar sobre os fatores condicionantes (sobretudo os obstáculos) dos processos de constituição do campo de conhecimento ambiental. Em termos metodológicos, as indagações são feitas a partir de um eixo epistêmico (centrado na ideia de coevolução), seguidas de desdobramentos teóricos (centrados na ideia de coexistência) e metodológicos (centrados na interdisciplinaridade) reivindicados pelo próprio campo emergente. A despeito de explicitar alguns elementos constituintes do novo campo, a contribuição central do artigo é a constatação de que o fundamento epistêmico reducionista, a despeito de ser um dos principais obstáculos epistemológicos a ser superado, não consegue conter os processos de constituição do novo campo de conhecimento ambiental.

Palavras-chave: epistemologia ambiental; coevolução; coexistência; interdisciplinaridade; reducionismo.

ABSTRACT This article inquires about the conditioning factors (especially obstacles) of processes for the constitution of the field of environmental knowledge. The methodological strategy is centered in an epistemic axis (the idea of co-evolution), followed by theoretical (the idea of coexistence) and methodological (focusing on interdisciplinarity) developments claimed by the emerging field. The main contribution of the paper is the observation that the reductionism is one of the main epistemological obstacles to be overcome, but it cannot contain the processes of evolution of the new field of environmental knowledge.

Keywords: environmental epistemology; co-evolution; coexistence; interdisciplinarity; reductionism.

\section{Introdução}

O contexto que abriga as inquietações centrais deste artigo é o contexto do debate socioambiental contemporâneo, apreendido aqui como um campo de coexistência, de tensões, conflitos, mas igualmente de rearranjos e recomposições derivadas do cruzamento entre abordagens oriundas das ciências socioculturais e biofísicas (Souza-Lima \& Knechtel, 2012). Neste sentido, na perspectiva teórica o campo da Ciência Ambiental (CA) reivindica uma aproximação intencional entre ciências sociais e ciências biofísicas, vez que ganha consistência a ideia 
de que o "objeto" da (CA) emergirá da cooperação entre estes campos disciplinares (Sobral, Lima \& Philippi Jr., 2011). Para além de uma formação teórica híbrida, igualmente ganha força a ideia de formar profissionais capazes de formular/implantar políticas de gestão conservacionistas que protejam o ambiente biofísico, mas também as comunidades, o ambiente sociocultural.

Nesta mesma perspectiva, os aspectos metodológicos reivindicados pela CA estão centrados em uma interdisciplinaridade que não se restringe aos sistemas formais de conhecimento, pois está aberta a saberes caracterizados como não científicos. Por consequência, há uma necessidade imperativa de aproximar técnicas e métodos próprios das ciências sociais de técnicas próprias das ciências biofísicas. Os espaços para uma Ciência Ambiental disciplinar parecem estar sendo intencionalmente reconfigurados a partir de um contexto emergente, que se apropria das contribuições dos campos disciplinares acerca do conhecimento ambiental, tomando como referências outras bases epistêmicas.

Em síntese, no contexto das CA há uma explícita intencionalidade de valorizar práticas coletivas de produção, acesso e validação de conhecimentos, tomando como ponto de partida o abandono ou a minimização da ideia de dissociação e adotando o princípio da (re) conciliação entre civilizações e ambientes biofísicos, um tipo de coevolução (Norgaard, 1994), tomado aqui como um dos principais fundamentos epistêmicos do campo emergente. Neste contexto, justifica-se o esforço deste artigo de indagar sobre os elementos fundantes (sobretudo os obstáculos) deste campo emergente.

Partindo da suposição de que já existe um campo de conhecimento ambiental, em uma perspectiva fundamentalmente teórico-reflexiva, o objetivo deste artigo é indagar sobre os fatores condicionantes (sobretudo os obstáculos) dos processos de constituição do campo de conhecimento ambiental. No curso deste raciocínio, serão enfrentadas as seguintes perguntas norteadoras:

1. Que fundamentos epistêmicos, teóricos e metodológicos permitem identificar os contornos do campo de conhecimento ambiental?

2. Que obstáculos têm sido enfrentados pelo novo campo para se constituir de forma autônoma?
Além da introdução e das considerações finais, o artigo está estruturado em duas seções. Na seção 2, tomando como referência o fundamento epistêmico reducionista, são apresentados os elementos constitutivos dos campos disciplinares do conhecimento. Se na seção 2, o fundamento epistêmico reducionista é caracterizado como fonte inspiradora para os campos disciplinares, na seção 3 são identificados seus limites com vistas a caracterizá-los como obstáculos aos processos de institucionalização e consolidação do campo de conhecimento ambiental.

\section{Singularidades dos campos disciplinares}

A ideia-força desta seção é refletir, mas principalmente tensionar os fundamentos epistêmicos, teóricos e metodológicos dos campos disciplinares de conhecimento, com vistas a identificar limites e potencialidades destes fundamentos no que se refere aos processos de constituição e consolidação do conhecimento ambiental.

\subsection{O reducionismo e a autoafirmação dos campos disciplinares}

Como fundamento epistêmico, o reducionismo que emerge a partir do cogito ergo sum (duvido logo sou) de Descartes pode ser apreendido como a busca de um fundamento último, um absoluto universal que sirva de base explicativa para a Ciência que emergia na modernidade, à medida que transforma o ambiente biofísico e sociocultural em algo que está posto diante do cogito, tal como um objectum. Nesta perspectiva, está estabelecida a (dis)sociação radical entre Homo sapiens e ambiente biofísico como fundamento último da episteme moderna, cuja história precisa ser apreendida a partir deste clamor por um estatuto canônico próprio para o conhecimento científico em relação ao conhecimento filosófico. Esta (dis)sociação entre conhecimento científico e conhecimento filosófico pode ser datada a partir dos séculos XV e XVI em diante, com as descobertas de Copérnico, Bacon, Galileu, Kepler e Newton (História da Filosofia, 1999; Stengers, 2002), dentre outros. O elemento fundante que permite delimitar o contorno desta episteme científica moderna é o reducionismo, que 
se constitui por intermédio do seguinte tripé: ruptura-construção-verificação (Quivy \& Campenhoudt, 2008). A ruptura está associada ao afastamento das prenoções ${ }^{1}$ dos preconceitos inerentes ao sujeito cognoscente; a construção está associada à capacidade de o sujeito cognoscente produzir conhecimento por meio da razão; e a verificação está associada à necessidade de verificar se o conhecimento elaborado racionalmente corresponde à empiria. Este reducionismo, ao ser justificado e afirmado filosoficamente por Descartes (1999) e Kant (1999), contribui de forma inexorável com o estabelecimento do contorno da episteme científica moderna ${ }^{2}$, centrada nos fenômenos físicos.

Com o propósito de se despojar de todos os preconceitos, de todos os deuses e demônios, de todas as influências derivadas do mundo das contingências (empiria), Descartes ajuda a fundar uma episteme cujo centro é a negação radical de tudo que puder ser negado, a dúvida metódica, absoluta e negante de tudo que estiver associado ao mundo da doxa. Neste sentido, a primeira parte do programa epistêmico de Descartes é a negação de tudo que for contingente, com vistas a alcançar um ponto de convergência universal entre os seres racionais. Se por meio da dúvida negante é possível negar tudo que pode ser negado, chega um momento em que a dúvida se depara consigo mesma. Ao deparar-se consigo mesma, irrompe o princípio fundante da episteme cartesiana, o único fundamento que tem o poder de negar tudo, inclusive a si mesmo, no sentido contingente ou empírico-corporal. Este absoluto que Descartes acredita ter descoberto é o "eu" não no sentido corporal, contingente, relativo e finito, mas no sentido transcendental, não contingente, infinito. A crença de Descartes é que, ao se libertar de todas as expressões das contingências ${ }^{3}, o$ cogito se abre a todas as possibilidades de (re)conciliação universal com outros cogitos.

Se esta interpretação da episteme moderna, afirmada a partir do cogito cartesiano, for aceita como parcialmente verdadeira, todas as formas de epistemi- cídios, denunciadas por Sousa Santos e outros autores (2005), patrocinadas ou contidas nos projetos de colonização europeia, não receberiam o aval da episteme de Descartes, pois todos os epistemicídios ocorreram e ocorrem no mundo das contingências (finito), não do cogito (infinito). O sentido de conquista, presente na episteme de Descartes, precisa ser apreendido no contexto do cogito não como conquista material, mas como possibilidade de conciliação. É oportuno ter presente que a maior preocupação de Descartes não é com o mundo das contingências, mas com o universal, o absoluto, o infinito, o cogito, pois tudo que não é cogito é efêmero, é contingente, é finito, é secundário para os interesses epistêmicos do filósofo francês.

Ao que parece, ao contrário da maioria das críticas, que associa os projetos megalomaníacos das tecnociências à episteme de Descartes, esta é um convite ao desapego em relação ao mundo das contingências, é um convite à contenção. Antes de se lançar de forma atabalhoada na direção da conquista do mundo das coisas e das contingências, o cogito cartesiano sugere que é preciso dar um passo atrás com vistas não a conquistar, mas a se reconciliar com o universo. Contudo, no âmbito do presente artigo, este recuo sistemático do cogito cartesiano, ao contrário de suas intenções emancipatórias e universalistas, inspirou a afirmação de um fundamento epistêmico reducionista que blindou os campos disciplinares, projetando-se como um obstáculo a qualquer tipo de diálogo entre eles. O fundamento epistêmico reducionista, derivado de Descartes, promoveu processos exacerbados de autoafirmação dos campos disciplinares.

\subsection{O reducionismo e as ciências sociais}

A despeito da gênese do reducionismo estar relacionada à fundação da episteme das ciências físicas (química e física), ele igualmente se torna fonte de inspiração para as "ciências da cultura" (Weber, 1977) - Sociologia,

\footnotetext{
${ }^{1}$ É provável que um dos primeiros a declarar guerra às prenoções tenha sido Francis Bacon, com sua teoria dos ídolos (Bacon, 1999).

${ }^{2} \mathrm{O}$ projeto científico de Galileu (1999) esboçando as leis fundamentais do movimento, que lhe confere o título de fundador da ciência moderna, está centrado em três premissas: a) observação; b) experimentação; c) uso de fórmulas matemáticas o mais simples possível para traduzir os fenômenos físicos. Descartes se inspira nas ideias simples derivadas das fórmulas matemáticas.

${ }^{3}$ A libertação em relação às contingências é o equivalente à "fuga da caverna", à negação radical da vulgaridade da doxa, de Platão (1999).
} 
Antropologia, Economia, Direito, Psicologia, etc. Por meio do reducionismo, cada campo seleciona e define seu objeto e seu método, conquistando assim o direito de definir e dizer o que pode ou não ser caracterizado como "verdade" acerca das questões associadas ao seu campo específico (Figura 1). O fundamento epistêmico reducionista possibilita a delimitação e a blindagem de cada campo específico de conhecimento.

A Figura 1 apresenta de forma sintética as relações entre reducionismo e a constituição das epistemes fundantes das ciências sociais modernas. $\mathrm{O}$ item 1 representa o período clássico da episteme, que compreende a antiguidade grega e o período medieval. Naquele período, a episteme se confunde com a filosofia. O item 2 representa o momento de ruptura da episteme em relação à filosofia por intermédio do reducionismo reivindicado pela ciência com acento na experimentação. O item 3 representa o momento de fundação dos campos específicos de conhecimentos socioculturais. Finalmente, no que se refere às questões próprias da episteme moderna, é possível ressaltar que são questões ausentes nas fases anteriores da história da epistemologia. No período moderno, emerge de forma original a nítida (dis)sociação entre aquele que produz o conhecimento a partir da razão - o sujeito cognoscente - e o ambiente transformado em objectum. A Figura 1, portanto, permite a visualização dos contornos da episteme das ciências físicas, mas igualmente inspiradora das ciências sociais.

\subsection{A episteme reducionista e suas tendências}

Tomando como referência o fundamento epistêmico reducionista, ao longo do século XX é possível identificar uma episteme científica moderna com três tendências que se afastam entre si. No entender de Bombassaro (1992), a primeira tendência é a analítica, herdeira direta de Descartes e Kant, pois o seu núcleo é a precisão e a clareza analítica. Trata-se da tendência epistemológica inspiradora, mas consolidada pelo conhecido Círculo de Viena (Pepe, 2007).

A segunda tendência, menos fiel ao fundamento epistêmico reducionista, ao atacar a primeira tendência, se autodeclara (sócio-)histórica. Minimiza o critério matemático como recurso de busca dos universais e passa a priorizar a empiria no sentido (sócio-)histórico. Nesta

\section{EPISTEME = Filosofia}

\section{Episteme = Ciência}

Reducionismo

\section{Ruptura \\ 2. Construção \\ 3. Verificação}

\section{Economia Direito Sociologia Antropologia}

Psicologia

Perguntas fundantes da episteme Moderna (CIÊNCIA):

Pode o sujeito apreender ou conhecer realmente o objeto?

Qual a origem dos conteúdos de consciência cognoscente: da razão ou da

experiência?

Em que consiste o conhecimento?

Há outro conhecimento além do racional?

Qual o critério que nos diz se um conhecimento é ou nãoverdadeiro?

FIGURA 1 - Reducionismo e episteme humano-social moderna.

FONTE: História da Filosofia (1999); adaptação do autor. 
tendência, há esforços que servem como indicadores da "coexistência" entre fatores internos e externos ao campo de qualquer conhecimento.

Do ponto de vista teórico, a tendência analítica, em busca da pureza teórica exigida pela calculabilidade matemática, não leva em conta a ideia de coexistência, talvez por entender que qualquer indício de coexistência seria uma porta de entrada ou foco de contaminação do "verdadeiro" conhecimento, do critério universal, capaz de unificar toda a Ciência. A despeito das duas tendências antagônicas e rivais, nas formulações de Bombassaro há o reconhecimento de que a episteme derivada da ciência dos séculos XV e XVI é a episteme que legitima e consolida todos os campos de conhecimento, inclusive o das ciências sociais.

A Figura 2 toma como referência as obras de Bombassaro (1992) e Mayr (2005) para tentar representar a episteme que, a despeito de ser contestada, continua servindo de suporte aos processos de produção de conhecimento da modernidade e suas respectivas tendências. De forma proposital, as setas indicam que não há diálogo entre as tendências epistêmicas derivadas de uma matriz predominante. Cumpre ressaltar que as formulações de Bombassaro limitam-se a apresentar as tendências analítica e (sócio-)histórica, deixando o espaço aberto para o biólogo Ernst Mayr reivindicar um estatuto canônico próprio para a ciência biológica.

A tendência analítica se constitui e se consolida antes da primeira metade do século XX, ao passo que as outras duas tendências ganham projeção a partir da

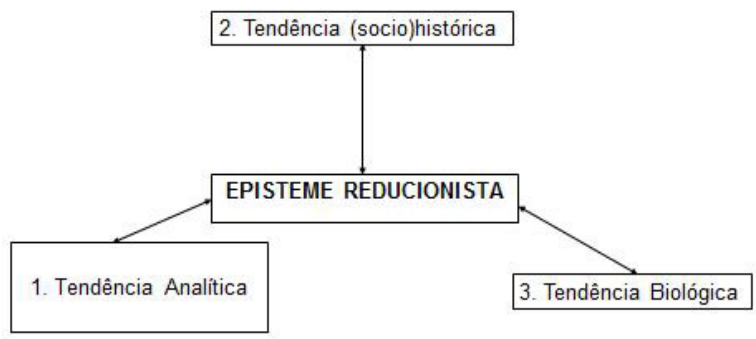

FIGURA 2 - Tendências no interior da episteme reducionista. FONTE: Bombassaro (1992); adaptação do autor segunda metade do mesmo século. A principal reivindicação da tendência analítica é a pureza do conhecimento científico, a ser conquistada por intermédio da unificação dos métodos de produção e, sobretudo, de validação dos conhecimentos. O grupo que alavancou esta tendência foi o (re)conhecido Círculo de Viena, representado por pesquisadores da estatura de Karl Popper (2003) com seu racionalismo crítico; Hans Kelsen (2012) com sua reivindicação de "pureza" para o campo jurídico; Ludwig Wittgenstein (1999) com sua filosofia da linguagem. Trata-se de uma tendência que se propõe a levar às últimas consequências a busca de um conhecimento válido universalmente.

A tendência (sócio-)histórica irrompe como contraponto à tendência analítica e se constitui reivindicando espaço para os componentes ignorados pela primeira tendência, os componentes (sócio-)históricos, tomados como condicionantes dos processos que produzem e validam conhecimentos com pretensões científicas. Os principais nomes vinculados a esta tendência, conforme a classificação de Bombassaro, são Thomaz Kuhn, Imre Lakatos e Paul Feyerabend, como primeira geração. Na segunda geração estão Gaston Bachelard, Georges Canguilhem e Michel Foucault; e na terceira geração estão Theodor Adorno e Jürgen Habermas ${ }^{4}$.

A terceira e última tendência, a biológica, escapou à análise atenta de Bombassaro. Para tanto, é imperativo recorrer não a um epistemólogo externo ao campo, mas a um biólogo preocupado em explicitar os elementos fundantes do próprio campo do qual faz parte. Mayr se esforçou desde o início a construir um estatuto filosófico-epistêmico para a biologia, pois a episteme da Física/ matemática era insuficiente. Na revisão da exígua literatura que ele fez - entre 1970 e 2000 - sobre a filosofia da biologia, toda ela recorre à mesma "estrutura epistemológica dos livros sobre filosofia da física" (Mayr, 2005 , p. 19). Trata-se de uma literatura que varia entre o vitalismo (filosofia baseada na força oculta ou virtude vital) e o mecanicismo cartesiano (todo organismo é uma máquina). Na resistência dos fisiologistas, os fisicalistas queriam "promover a verdade segundo a qual não há outras forças ativas no mundo orgânico além das forças

\footnotetext{
${ }^{4}$ Para Habermas, que se autodeclara "pós-empirista", a obsessiva busca pela "pureza" do conhecimento científico transforma a tendência analítica em ficção.
} 
físicas e químicas comuns" (Mayr, 2005, p. 84). Neste campo de disputas, o fundamento epistêmico reducionista da física tenta se consolidar como fundamento hegemônico, racional, empírico e antimetafísico, pois o vitalismo passou a ser visto como símbolo das forças ocultas e sobrenaturais, absolutamente distinto da ideia de forças físicas ou naturais. A principal ambição de Mayr é suprir esta lacuna e, ao realizar isto, oferece pistas para se pensar novos fundamentos epistêmicos não apenas para a biologia, mas também para os contornos do novo campo de conhecimento ambiental.

Isto parece se comprovar à medida que Mayr torna explícita sua opção pelo "organicismo holístico", ao caracterizar o fundamento epistêmico reducionista como uma crença filosófica herdada dos fisicalistas, cujo pressuposto é que "a explicação só poderia ser alcançada no mais baixo nível de organização" (Mayr, 2005, p. 22). Para o campo da biologia, isto é impossível, vez que o nível mais baixo implica fuga da biologia e avanço para o campo das ciências físicas. Ele está admitindo que o princípio da (dis)sociação entre um sistema vivo e seu contexto, comum ao reducionismo fisicalista, é um obstáculo para a produção de conhecimento no campo da biologia, pois este exige a inseparabilidade entre sistema vivo e seu contexto. Em seus próprios termos, “[...] ninguém conseguiria inferir a estrutura e a função de um rim caso recebesse um catálogo completo de todas as moléculas de que está composto (Mayr, 2005, p. 89)".

Este exemplo do rim é esclarecedor, pois demonstra os limites do reducionismo transposto da episteme da física para o campo da biologia em particular e para o conhecimento ambiental, em geral. Contudo, cumpre ressaltar que o fundamento epistêmico reducionista, a despeito deste arsenal de questionamentos e contestações, continua resistindo, ora como fonte de inspiração para os campos disciplinares, ora como obstáculo, no sentido tomado por Bachelard (1974), para o campo de conhecimento ambiental.

\section{Singularidades do campo ambiental}

Se a ideia-força da seção 2 foi apresentar o fundamento epistêmico reducionista como fonte central de inspiração e de consolidação dos campos disciplinares, nesta seção a ideia-força é identificar alguns de seus limites para o campo ambiental. Para tanto, são indicadas algumas das principais obras inspiradoras dos fundamentos epistêmicos, teóricos e metodológicos que permitem identificar os contornos do campo de conhecimento ambiental. São obras que permitem tornar visíveis alguns elementos constituintes que singularizam o campo de conhecimento ambiental, porém sem pretensões de esgotar, mas de contribuir com o debate.

\subsection{O "objeto ambiental" como um emaranhado}

$\mathrm{Na}$ perspectiva dos campos disciplinares mais próximos ao ambiente sociocultural, é possível destacar as obras de Pádua (1987 e 2002); Guha (1994), Norgaard (1994), Leis (1999), Ferreira (1998), Goldblatt (1998), Cavalcanti (1999 e 2003), Foladori (2001), Leff (2001a; 2001b; 2006 e 2009), Abramovay (2002), Vieira e Weber (2002), Morin (2003; 2005a; 2005b; 2010), Latour (2004), Beck (2006), Sachs (2007), Giddens (2010), Martínez-Alier (2011), dentre outros. E dos campos disciplinares mais próximos ao ambiente biofísico é possível destacar as obras de Prigogine e Stengers (1984), Serres (1991; 2011), Deléage (1993), Bateson (1993), Prigogine (1996), Capra (1996; 2002), Sheldrake (1997; 2001), Stengers (2002; 2004), Mayr (2005), Dawkins (2007).

Há monografias, dissertações, teses e artigos que se projetam no cenário do debate socioambiental, todos inspirados nos achados e contribuições destes autores. Nos termos de Floriani (2001; 2004a; 2004b e 2006), os conhecimentos que emergem e permitem delinear fronteiras deste novo campo de conhecimento têm se caracterizado como "objetos complexos" e com potencialidades para fundar "ciências em trânsito", difíceis de serem domesticadas por uma episteme fiel a um fundamento reducionista. Qualquer formulação teórica, esteja ela ancorada no domínio sociocultural ou biofísico, que incorpora ou leva em conta o ambiente biofísico, começa a se definir à medida que leva em conta o caráter fugidio e complexo de seu novo objeto.

Ao contrário do fundamento epistêmico reducionista, que permite a cada campo disciplinar aprisionar seu objeto tal como uma propriedade privada, o "objeto 
ambiental" não se deixa aprisionar facilmente. Concebido como um emaranhado que deriva simultaneamente do ambiente sociocultural (escolhas e decisões civilizatórias) e do ambiente biofísico, este objeto singulariza-se por ser um objeto sem território fixo (Figura 3).

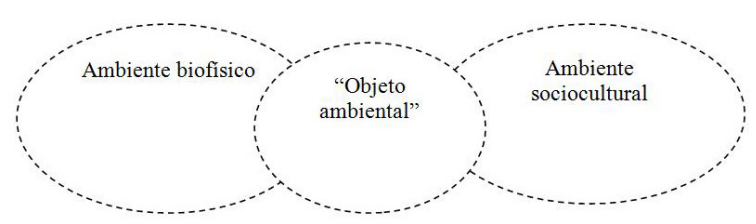

FIGURA 3 - Representação do "objeto ambiental".

Um exemplo ilustrativo que permite identificar este "objeto ambiental" pode ser extraído a partir da análise de um fenômeno fundamentalmente natural, mas que é potencializado a partir das escolhas e decisões civilizatórias derivadas do ambiente sociocultural. Trata-se da eutrofização, fenômeno que na origem está associado ao aumento de algas microscópicas próximas à superfície, o que impede a penetração de luz na água e, por sua vez, a realização da fotossíntese em camadas mais profundas, provocando a morte de algas que estão abaixo da superfície. A concentração de algas mortas favorece o aumento das bactérias decompositoras, que consomem muito oxigênio para realizar a decomposição. A falta de oxigênio na água provoca a morte de peixes e outros organismos aeróbicos. Com a falta de oxigênio, a decomposição de matéria orgânica, que inicialmente era aeróbica, passa a ser anaeróbica, aumentando a produção de gases tóxicos, como o gás sulfídrico $\left(\mathrm{H}_{2} \mathrm{~S}\right)$ (Odum, 1983; Ricklefs, 1996).

Se fosse possível isolar o fenômeno da eutrofização, ele poderia ser caracterizado como um "objeto" específico e exclusivo do campo biofísico. Contudo, a pesquisa interdisciplinar conduzida por Cunha et al. (2011) demonstrou que o fenômeno da eutrofização é potencializado pelas escolhas civilizatórias, à medida que as práticas variadas de um grupo social - uso de fertilizantes, agroquímicos, esgotos domésticos e industriais - aumentam a quantidade de organismos no corpo d'água, favorecendo a eutrofização. Esta eutrofização potencializada pelas escolhas civilizatórias é o emaranhado representado na Figura 3, o "objeto ambiental". Não se trata de um "objeto" de estudo exclusivo nem do campo biofísico, nem do campo sociocultural, mas de ambos.

Em certa medida, as contribuições dos autores citados nesta seção estão orientadas para este objeto desterritorializado e, em função disto, contribuem com os processos de constituição e consolidação dos fundamentos epistêmicos, teóricos e metodológicos do campo ambiental. Em suma, cada autor citado, a seu modo, identifica limites na episteme que tem servido de apoio aos aportes teórico-metodológicos da questão ambiental. A identificação de limites, por sua vez, abre caminho para novos aportes que, ao exigirem fundamentos menos rígidos, definem novos contornos para o campo de conhecimento ambiental.

\subsection{O reducionismo como obstáculo epistêmico}

Tomando como referência a minuciosa investigação de Bombassaro, há indícios ${ }^{5}$ de que a episteme centrada em um fundamento reducionista estimulou a apropriação ${ }^{6}$ (Serres, 2011) do ambiental de forma positiva pelos campos biofísicos (as tendências analítica e biológica) e de forma negativa pelos campos sociais (a tendência histórica). Neste sentido, diante das formas diferenciadas de lidar com o ambiental, parece oportuno indagar como cada uma das tendências epistêmicas incorpora e representa o ambiental (Figura 4).

Conforme a Figura 4, na tendência analítica, o ambiental é representado e apropriado como um cálculo matemático, como um sistema morto, pois é apreendido como o local onde será realizado o teste da hipótese, nos moldes inspirados em Popper (2003). Nesta tendência, o núcleo da pesquisa e do conhecimento é a construção racional, não o mundo vivo. Na tendência (sócio-)histórica, nos limites da abordagem e dos interesses de pesquisa de Bombassaro, o ambiental sequer é representado, é uma dimensão que não é levada em conta. Para além da contribuição de Bombas-

\footnotetext{
${ }^{5}$ Os indícios são indiretos, pois o núcleo da investigação de Bombassaro não é o ambiental, ao menos no sentido conferido por Mayr, como um sistema vivo.

${ }^{6}$ A ideia de apropriação aqui está ancorada nas formulações de Serres, como o ato de imprimir uma marca em alguma coisa.
} 


\section{Tendência epistêmica Representação do ambiental}

Analitica

cálculo matemático (sistema morto)

(Socio)histórica

dimensão que não é levada em conta

Biológica

sistema vivo

FIGURA 4 - Representação do ambiental nas tendências epistêmicas. FONTES: Bombassaro (1992); Mayr (2005); adaptação do autor.

saro, de forma radicalmente distinta das duas tendências anteriores, na tendência biológica, o ambiental conquista status de um sistema vivo (Mayr, 2005).

As três formas de apropriação e de representação do ambiental revelam a potencialidade da episteme reducionista produzir sentidos precisos, sobretudo por meio das tendências 1 e 3 , e refinados acerca do ambiental. Por outro lado, o excesso de precisão herdado do fundamento epistêmico reducionista projeta-se como um obstáculo (Bachelard, 1974) para qualquer tentativa de diálogo com as outras tendências componentes da episteme. Neste sentido, o limite da episteme reducionista de tratar o ambiental de forma dialógica precisa ser buscado no interior dela mesma. Este limite talvez seja o principal obstáculo para instituir um campo específico do conhecimento ambiental. Como fundar um campo que resulte do diálogo epistêmico, teórico e metodológico, mas que tome como ponto de partida uma episteme solidamente instituída em bases reducionistas, sem tradição nem pretensão explicitamente dialógica?

Neste particular, outro desafio que se apresenta é: como fugir à tentação da disciplinarização de um conhecimento que tende a escapar dessa tendência controladora?

Um dos primeiros problemas é que a ideia de campo tem uma dívida profunda com o fundamento epistêmico reducionista e o "campo" do conhecimento ambiental reivindica fundamentos epistêmicos que, a despeito de levar em conta o reducionismo, tenciona superá-lo. O novo "campo" tenciona constituir-se no diálogo entre os elementos fundantes do reducionismo e outros fundamentos originários de outras matrizes de pensamento, inclusive sem o "selo" da cientificidade; conhecimentos "não-científicos" (Philipphi Jr. \& Silva Neto, 2011).

\subsection{Coevolução como fundamento epistemológico}

$\mathrm{Na}$ institucionalização do campo ambiental, um dos primeiros desafios a ser enfrentado parece ser o desafio interno aos próprios subcampos. Por exemplo, como instigar a Sociologia, cuja consolidação como campo de conhecimento do social está fortemente associada ao fato de dar as costas ao ambiental (Durkheim, 2002), a incorporar em suas análises acerca do "desenvolvimento" elementos do ambiente biofísico?

O fenômeno da coevolução é originário dos campos biofísicos (Dawkins, 2007), pois está associado aos processos de coevolução dos seres e sistemas vivos. Contudo, para os propósitos deste artigo, a coevolução, ao possibilitar a aproximação entre os campos socioculturais e biofísicos e, por consequência, permitir a identificação dos contornos do "objeto ambiental” (Figura 3), é apreendida como um fundamento epistêmico.

Se de um lado a ideia de desenvolvimento permitiu às ciências sociais estabelecer suas fronteiras em relação às influências do mundo biofísico, de outro, serviu para isolá-las. O mesmo raciocínio pode ser feito sobre as ciências biofísicas, centradas na ideia de evolução sem levar em conta as escolhas civilizatórias, todas elas imbricadas e condicionantes das mudanças nos processos evolutivos. O conceito de coevolução permite abertura de brechas nestas fronteiras fortemente blindadas, vez que se propõe a produzir novos sentidos acerca do ambiental, levando em conta os processos recíprocos de contaminação, mas igualmente de fertilização dos campos sociais e biofísicos.

No entender de Foladori e Tommasino (2000) e, de forma mais enfática, do economista estadunidense Richard Norgaard, talvez o primeiro autor a usar o conceito de "coevolução" como fundamento epistêmico, 
o ambiente condiciona a adequação de como as pessoas se comportam quando guiadas por modos alternativos de conhecimento, formas de organização social e tipos de tecnologias. [...] Em qualquer ponto no tempo, um condiciona o outro. Ao longo do tempo, nenhum é mais importante que o outro. [...] Assim, a perspectiva coevolucionária explica por que opções são incomodamente limitadas no curto prazo; a cultura tem condicionado o ambiente e o ambiente tem condicionado a cultura. Em cada ponto no tempo há uma quase pane total de conhecimentos, valores, tecnologias, organização social e ambiente natural coevoluídos. [...] Onde estaremos no porvir não é condicionado pela cultura de hoje nem pelo ambiente apenas, mas por estes e inúmeros fatores futuros também imprevisíveis (Norgaard, 1994, p. 46; tradução nossa).

A mensagem escondida do trecho de Norgaard é um convite para pensar o ambiental não mais em conformidade aos limites do reducionismo, mas a partir das fronteiras de cada campo específico, o que implica pensá-lo como (socio)ambiental, como condicionante da vida humana, mas igualmente como condicionado por ela. A coevolução é um fundamento epistêmico que leva em conta a necessidade de (re)conciliação do Homo sapiens com o ambiente biofísico e sociocultural. Este fundamento é, no mínimo, distinto do fundamento da episteme reducionista, centrado na (dis)sociação entre Homo sapiens e ambientes externos (Seção 2).

A partir da coevolução, é possível vincular a este novo fundamento epistêmico os elementos teóricos, sintetizados na ideia de "coexistência" (Souza-Lima \& Knechtel, 2012) entre abordagens sociais e biofísicas, e finalmente os elementos metodológicos, sintetizados na ideia de "interdisciplinaridade" (Philipphi Jr. \& Silva Neto, 2011).

\subsection{Interdisciplinaridade e ciência ambiental}

Na história das ciências que se constituíram sem levar em conta os vínculos de interdependência entre
Homo sapiens e ambiente biofísico, a disciplinaridade pode ser caracterizada como um campo monocultor de saberes, à medida que induz o pesquisador que dele faz parte a se viciar e cultuar suas próprias crenças. Envolvido nesta monocultura, o pesquisador aprende a viver e interagir com o mundo a partir, apenas, de si mesmo, pois é próprio de uma monocultura reforçar a mensagem de que ela é capaz de bastar-se a si mesma (Seção 2).

Embora Kant (1999) não tenha feito referência aos sistemas monocultores do saber, pode ser considerado um de seus fundadores ao instituir uma episteme para a ciência derivada de Newton (História da Filosofia, 1999), centrada no sujeito cognoscente. Para o filósofo de Königsberg (pequena cidade da Prússia), a principal virtude do sujeito cognoscente é a capacidade de se desvincular do ambiente (objeto) para compreendê-lo. A ideia de controle que emerge deste processo envolvendo sujeito e ambiente está associada à necessidade do sujeito controlar racionalmente a produção do conhecimento. A ideia de controle precisa ser apreendida como (auto) controle do sujeito para não extrapolar sua explicação para além dos limites da empiria e da razão.

Neste sentido, o princípio do "bastar-se a si mesmo"7 - outra forma de caracterização do reducionismo ou do (auto)controle do sujeito cognoscente de Kant - aparece na base dos campos disciplinares do conhecimento científico moderno, só que ressignificado. A ideia de (auto)controle é substituída pela ideia de controle do ambiente pelo sujeito. É sempre oportuno lembrar que na base do projeto epistêmico de Kant está o irredutível princípio do dever, o imperativo categórico, que é o suficiente para que se tenha uma compreensão de que o sujeito cognoscente kantiano é o sujeito contido, o antípoda do sujeito orientado para a conquista. O fato é que o sujeito cognoscente responsável pela constituição dos campos disciplinares não é o sujeito contido, mas o sujeito conquistador do ambiente, caracterizado como "objeto" de estudo. O movimento de conquista avança para outros estágios de blindagem do campo, impossibilitando qualquer diálogo com outros campos.

\footnotetext{
${ }^{7}$ O princípio do "bastar-se a si mesmo" extraído do projeto epistêmico de Kant precisa ser apreendido no interior de uma discussão mais alargada. Kant, como um dos grandes nomes do Iluminismo, buscou de forma obsessiva fundamentos para o conhecimento científico no próprio Homo sapiens, não fora dele. Este fundamento é a razão.
} 
A interdisciplinaridade parece surgir neste contexto contemporâneo como uma prática que se propõe a possibilitar a abertura de espaço para a civilização de novas vivências associativas no que se refere à produção, acesso e validação de conhecimentos. Este desassossego explica e justifica a constituição de programas de pós-graduação, em níveis de mestrado e doutorado, com pretensões interdisciplinares e com vistas ao enfrentamento de temas que exigem dos sujeitos cognoscentes esforços e empreendimentos que conduzam as abordagens disciplinares para além das fronteiras de seus campos. Seguindo a linha deste raciocínio, a prática interdisciplinar pode ser apreendida não como uma tentativa ingênua de desqualificar os campos disciplinares, mas como (re)valorização, pois não faz sentido pensar práticas interdisciplinares sem o acúmulo e a história dos campos disciplinares (Cunha et al., 2011).

Face a esta primeira bateria de questionamentos que aponta para novas formas de reconstituição dos campos disciplinares, irrompem algumas indagações que reivindicam outras formas de produzir/acessar/ validar conhecimentos. É o que veremos nas próximas subseções.

\subsection{Um outro olhar-e-ver dos sistemas e criaturas vivas}

Como já foi apresentado (Seção 2), o pressuposto fundante da era moderna (em sua matriz eurocêntrica) continua sendo a separação entre corpo/matéria/máquina e mente/espírito, ou a dissociação radical entre Racionalidade e Imaginário, pressuposto herdado de Descartes (1999), Kant (1999), etc. Talvez não tenha sido a intenção de Descartes e Kant, mas o fato é que eles inspiraram o início da quebra da unidade do mundo ao reforçar a noção de corpo/máquina como algo decifrável pela Ciência positivista. De outra parte, a mente/espírito emerge como dimensão indecifrável e inatingível.

Os reflexos desse pressuposto em todos os domínios da vida associativa ainda não foram assimilados nem compreendidos em todas as dimensões. Tome-se como referência o sistema de aprendizagem. Dependendo do modo como é orientado, o aprendente tende a se tornar insensível ou cego ao vínculo de interdependência que liga o mundo e a existência das criaturas vivas e não vivas. Ao aprender, quando criança, que o corpo humano é uma divisão absoluta entre cabeça, tronco e membros, o aprendente moderno é induzido a construir barreiras que o impossibilitam de enxergar e sentir o cimento que amarra cada uma das partes do corpo humano, entre si e em relação ao ambiente biofísico. O lado mais perverso deste processo de dissociação é que o aprendente cresce e amadurece desdenhando desse "ponto cego" (Maturana \& Varela, 2001) que sustenta sua (de)formação. Com o passar dos anos, a tendência é a cristalização da crença na separação entre cabeça, tronco e membros. O aprendente aprende a acreditar que quem pensa diferente dele está na fronteira da irracionalidade. Para esse tipo de aprendente, desenvolver outras formas de pensar torna-se um obstáculo quase intransponível. Sendo assim, o "olhar-e-ver" instituído pela episteme reducionista moderna tende a ensinar ao aprendente o ofício de dividir para dominar. $\mathrm{Ou}$, de forma mais contundente, dividir para fazer calar aquilo que é representado como "objeto" de estudo (Stengers, 2002). Nessa forma singular de apropriação do ambiente, há pouco espaço para a beleza presente no cimento invisível que impede a separação entre cabeça, tronco e membros.

Um outro "olhar-e-ver" - menos refém do fundamento epistêmico reducionista - tem pretensões de se comunicar com o corpo, não de escravizá-lo (Leff, 2009). Com esta minimização do reducionismo, talvez o profissional de qualquer campo monocultor de formação seja melhor capacitado para alinhavar os retalhos de sua formação fragmentada, orientado pela unidade do vínculo de interdependência e beleza que liga todas as criaturas e sistemas vivos. É possível que nessa direção estejam emergindo outras formas de fecundar os objetos científicos, com vistas não apenas a tornar visíveis, mas de suplantar as dimensões colonizadoras das racionalidades que sustentam o fazer científico moderno. É o que veremos na próxima subseção.

\footnotetext{
${ }^{8}$ A noção de ponto cego é uma das metáforas presentes na episteme cognitivista da escola chilena e tenta mostrar que um sistema teórico é incapaz de perceber por si mesmo seus próprios limites; a consequência disto é a necessidade do outro.
} 


\subsection{A contaminação dos objetos científicos}

Que vínculo pode existir entre "objeto limpo" e "objeto contaminado"?

O primeiro é derivado de práticas científicas centradas na "certeza", ao passo que o segundo emerge de práticas de produção de conhecimento centradas na "incerteza".

Um exemplo esclarecedor apresentado por Latour (2004) é o do amianto, que por muito tempo foi considerado um "objeto limpo" até suas características perversas e invisíveis materializarem-se em formas variadas de cânceres fulminantes. A partir disso, o amianto deixa de ser matéria inerte, pura, inocente e rentável para se tornar "objeto contaminado" e "contaminador". A passagem do status de herói a vilão é registrada nas vidas e nos corpos de algumas pessoas de forma não tão alegres, mas trágicas.

A Ciência com C maiúsculo e no singular continua insistindo na necessidade de se produzir "objetos limpos", sem os vícios e caprichos de seus produtores, os cientistas. Estes são produtos de uma Ciência que os mesmos tendem a reproduzi-la, tornando visível o conceito complexo de recursividade. Nesse modo de produção de conhecimento, a principal ideia é (dis)sociar o sujeito do objeto para garantir a pureza e a inocência de ambos. Produzir um conhecimento puro e cristalino significa manter a (dis)sociação entre sujeito e objeto, sociedade e natureza, corpo e mente, racionalidade e imaginário.

Seria possível produzir conhecimento puro sem essa (dis)sociação? Não se tem mais certeza se existe objeto puro, vez que tem aumentado a desconfiança em relação à pureza e à inocência dos objetos e dos sujeitos. Por outro lado, como corolário, aumenta a possibilidade de relaxar face às impurezas entranhadas nos objetos contaminados. O que muda, então, é o nível de compreensão e, em função disso, de tolerância à impureza. Junto à afirmação de que não há "objeto puro", está embutida outra afirmação; a de que a aceitação da impureza não exclui a necessidade de se produzir conhecimentos minimamente confiáveis e criticáveis. Produzir objetos impuros não significa negligenciar níveis elevados de rigor, mas apostar que é possível produzir conhecimen- to sem insistir na crença da pureza absoluta do objeto. A impureza de um objeto está associada à incursão do observador, com seus vícios e virtudes, no interior do objeto (Sheldrake, 2001).

Nessa linha de raciocínio, admitir a impureza como dimensão ou parte constitutiva do objeto implica admitir outra possibilidade de produzir conhecimento, sem compromissos maiores com a pureza; ao invés de negar o diálogo com outros atores e sujeitos, tende a convidá-los a se pronunciarem. Ao invés de induzi-los ao silêncio, conforme as provocações de Stengers (2002), propõe a abertura dialógica. Ao invés da disputa pelo conhecimento mais preciso, mais rigoroso e mais puro, irrompe uma possibilidade de cooperação com vistas a um conhecimento que, para compensar a precisão, o rigor e a pureza, institui o espaço da partilha e da solidariedade, sem abrir mão das intenções de diálogo com a verdade (Souza-Lima, Chiaramonti \& Maciel-Lima, 2011; Souza-Lima, Silva \& Braga, 2013; Silva et al., 2013).

Se o pressuposto da forma pura de produzir conhecimento, reinante nas ciências não ambientais, ancora-se na premissa de que o "outro" é dispensável, a forma impura, ao contrário, apoia-se no "outro". A forma impura de produzir/validar conhecimento não emerge de uma súbita generosidade ontológica presente em algumas pessoas ou grupos iluminados. Ao que parece, ela emerge de necessidades imperativas de produzir/validar conhecimentos que transcendam as insuficiências das formas supostamente puras. Não parece tratar-se de um novo tipo de "pentecostalismo", mas de outra possibilidade de cooperar aprendendo e de aprender cooperando.

Talvez estejam aqui algumas pistas para a compreensão dos avanços na direção da institucionalização da interdisciplinaridade como estratégia metodológica fundamental aos processos de institucionalização e de consolidação do campo de conhecimento ambiental (Philipphi Jr. \& Silva Neto, 2011).

\subsection{Estatuto metodológico para o conhecimento ambiental}

Cumpre ressaltar que o debate em torno da interdisciplinaridade não se trata de uma venda de ilusões, pois a mesma não pode ser entendida como a solução final 
para todos os problemas contemporâneos, muito menos como uma declaração de guerra aos campos disciplinares. A interdisciplinaridade pode ser apreendida como uma prática que tende a ampliar espaços de coexistência, capazes de aproximar abordagens que se constituíram como campos de conhecimento, ora competindo, ora se ignorando de forma recíproca, mas que podem desenvolver a capacidade de cooperar.

Contudo, a pergunta permanece, pois se a produção do conhecimento derivada das fronteiras entre campos disciplinares continua dependente de validações dos campos disciplinares, soa como inadequada ou provocativa a reivindicação de um estatuto metodológico próprio para as práticas interdisciplinares, a não ser que nesta disputa sejam demarcados dois estágios distintos, embora complementares:

1. Estágio da produção do conhecimento ambiental: aqui, os processos de produção do conhecimento interdisciplinar podem/devem reivindicar um estatuto metodológico próprio, vez que podem estabelecer alguns pré-requisitos que sirvam de balizas para estudos situados na interface sociedade/natureza. Podem/ devem, por exemplo, sugerir que estudos com esta característica acolham pesquisadores das ciências sociais e das ciências biofísicas;

2. Estágio da validação do conhecimento ambiental: aqui, os processos de validação e acesso desses conhecimentos produzidos interdisciplinarmente parecem dependentes em demasia de estatutos não apenas metodológicos, mas epistêmicos e teóricos dos campos disciplinares histórica, social e politicamente estabelecidos.

A partir dos dois estágios citados acima, é possível construir uma analogia que nos permita refinar a reflexão acerca dos limites e potencialidades dos campos disciplinares, bem como sobre as inevitáveis tensões entre eles e os campos que se propõem a produzir conhecimento à luz de práticas interdisciplinares. Tal como um estômago condicionado a um único tipo de dieta, um cérebro disciplinar é treinado (condicionado) a digerir apenas um tipo de alimento/conhecimento (monotonia intelectual), ao passo que um cérebro interdisciplinar passou por condi- cionamentos um pouco mais largos e, por consequência, consegue ter uma dieta mais diversificada. A questão que irrompe é a seguinte: um cérebro acostumado a uma monoalimentação intelectual e reflexiva pode servir de ponto de partida às práticas interdisciplinares?

Uma das exigências para determinada prática de pesquisa interdisciplinar é que os participantes tenham um cérebro vigorosamente treinado/condicionado em um campo específico de conhecimento. A expectativa que perpassa este pressuposto é a de que um cérebro bem treinado em um campo disciplinar específico poderá contribuir de forma efetiva com a prática interdisciplinar. O campo disciplinar seria o equivalente a um sistema cultural capaz de produzir indivíduos predispostos a perpetuar ou autoafirmar o próprio campo. Neste sentido, o ideal é que o indivíduo que migra do núcleo duro para as fronteiras do seu campo disciplinar tenha bem constituído o habitus (Bourdieu, 2006) de seu campo disciplinar. A troca e a cooperação com outros campos disciplinares está condicionada ao habitus.

Uma das dificuldades de aceitar de imediato este pressuposto associa-se ao fato de que um cérebro ensimesmado pode ser condição necessária, porém não suficiente, para o êxito da prática interdisciplinar. Invariavelmente, um cérebro excessivamente institucionalizado - habitus consolidado - pode se caracterizar como um obstáculo à prática interdisciplinar exatamente por ser excessivamente ensimesmado. Em termos alternativos, parece adequado que o cérebro seja, simultaneamente, ensimesmado, mas predisposto a uma abertura para o Outro. Isto nos induz a apreender a interdisciplinaridade não como uma vocação ou um processo espontâneo de aprendizagem, mas como uma escolha, uma educação da vontade, uma ética. Talvez isto explique ou justifique a concepção de Japiassu (1976), para quem a interdisciplinaridade está associada a uma ética atitudinal que implica admitir que, antes de esperar qualquer espontaneísmo ou voluntarismo, parece fundamental estimular atitudes interdisciplinares. Contudo, a dificuldade de aceitar a ética atitudinal de Japiassu é que esta pode ser apreendida como um convite à ideia de que é possível praticar interdisciplinaridade de forma monástica ou isolada. A interdisciplinaridade de um indivíduo só. 


\subsection{Monocultura versus policultura do conhecimento}

No bojo destas tensões, a pergunta de partida desta subseção tende a se desdobrar, pois se um cérebro monocultivado e uma atitude com inclinações interdisciplinares podem ser necessários, mas ainda não suficientes, o que está faltando?

Ao que parece, não está suficientemente demonstrado que a presença destes fatores constitutivos possa garantir o sucesso da prática interdisciplinar. É muito arriscado estabelecer regras a priori, pois algumas experiências demonstram que as práticas interdisciplinares precisam ser analisadas a posteriori ou durante sua vigência. Para tanto, os pesquisadores envolvidos poderiam recorrer à descrição pormenorizada de suas práticas, incluindo as possíveis influências recebidas de outros campos monocultores de saberes que impactaram em seu campo de origem. Por exemplo, um conhecimento pormenorizado de determinado ecossistema, ofertado pela ecologia, pode influenciar de forma decisiva um cálculo econômico que, sem esta contribuição da ecologia, teria como critérios outras referências, em geral, endógenas ao campo da ciência econômica instituída. Isto seria apenas um exemplo de consórcio entre campos disciplinares, todo ele orientado pela premissa de que qualquer campo ensimesmado de conhecimento tem dificuldade de enxergar e minimizar por si mesmo seus próprios limites teórico-compreensivos ou, nos termos de Maturana e Varela (2001), seus pontos cegos.

Resta investigar se o alargamento das fronteiras epistêmicas dos campos monocultores se caracteriza como ameaça ou possibilidade de reconstituição. Se isto for aceito como verdadeiro, o conhecimento híbrido derivado de práticas interdisciplinares, em lugar de estremecer as bases dos campos monocultores, tende a fortalecê-los. Parece apressado e equivocado associar o fim dos campos monocultores à ampliação e constituição de campos policultores de conhecimento.

Resta igualmente testar, em formato de hipótese, se é procedente ou não a afirmação preliminar de que o desenvolvimento de híbridos, ao tornar visíveis as insuficiências dos campos monocultores, anunciam e instituem as bases de seu fortalecimento. Para tanto, é imperativo catalogar experiências que evidenciem este movimento dialógico envolvendo híbridos e campos monocultores. É fundamental tentar localizar nas formulações teóricas já instituídas (sobre interdisciplinaridade e no domínio do emergente campo de conhecimento ambiental) estas mesmas relações dialógicas.

Em termos objetivos, a pergunta é a seguinte: a constituição dos híbridos fortalece (ou não) os campos monocultores de conhecimento?

Ao que parece, um campo monocultor se fortalece à medida que aceita enfrentar o desafio de incorporar elementos historicamente caracterizados como estranhos ao próprio campo. A distância entre a economia clássica, neoclássica ou até mesmo a economia ambiental e a etnoeconomia ${ }^{9}$ praticada por Cavalcanti (2002), por exemplo, é considerável. Os pressupostos que sustentam um sistema analítico fechado da economia neoclássica são insuficientes para produzir e validar conhecimentos produzidos a partir de pressupostos que fundam um sistema analítico aberto, tal como se apresentam a etnoeconomia em particular e o campo de conhecimento ambiental, em geral. A economia neoclássica (mesmo a autodeclarada ambiental) constitui-se e consolida-se a partir da crença de que seu cálculo é um cálculo "limpo", sem qualquer contato com as impurezas do mundo externo ao sistema econômico. Trata-se de um cálculo ensimesmado. A etnoeconomia funda-se em outras crenças, um pouco mais tolerantes em relação às impurezas externas. Aqui reina a ideia de que o conhecimento produzido nunca estará absolutamente isento de impurezas, pois estas são partes constitutivas e constituintes do mesmo.

No campo monocultor das teorias sociais, a sociologia clássica constitui-se e institui-se rejeitando possíveis contaminações derivadas dos campos monocultores da biofísica. Esta rejeição é compreensível e justificável à medida que os elementos fundantes de uma episteme social, em busca de um estatuto e de cânones próprios, não podiam ser apreendidos como se fossem determinados pela perspectiva biofísica. Se a episteme

\footnotetext{
${ }^{9}$ A contribuição de Cavalcanti é aqui apresentada como um dos principais indícios da Ciência Ambiental, vez que articula de forma original sistemas humanos e biofísicos, elemento fundante desta nova episteme.
} 
social aceitasse o determinismo biofísico, suas aspirações de autonomia cairiam por terra. É sempre importante lembrar a principal reivindicação de Durkheim (1988) acerca da caracterização da sociologia como ciência sui generis, pois, ao apresentar esta reivindicação, Durkheim estava rejeitando contaminações deterministas do domínio biofísico sobre o domínio social.

Nas formulações contemporâneas de Touraine (2006), o cânone estabelecido por Durkheim ressurge, mesmo que redefinido. Touraine afirma que sem o oxigênio o pensamento humano não poderia existir. Com esta afirmação, ele promove uma (re)conciliação, mesmo que parcial, entre os domínios biofísico e social da condição humana. Sua afirmação admite que a condição de existência do pensamento humano pressupõe uma base biofísica, o oxigênio. Contudo, seu argumento não para por aí, pois ele também complementa que não é o oxigênio, como base biofísica, que irá determinar o refinamento, a capacidade de agir por conta e risco do pensamento humano. No momento em que Touraine minimiza o suposto determinismo da base biofísica sobre o refinamento do pensamento humano, ele repõe e renova o cânone durkheimiano, vez que se a base biofísica é a condição sine qua non para o pensamento, não é ela, porém, que determina ao ser humano o que pensar de forma específica e por conta própria. O momento de escolher o que pensar é o momento da autonomia, da reconstituição do que Durkheim caracterizou como domínio sui generis, isto é, do social. Estar condicionado é diferente de ser determinado e esta parece ser a (re)conciliação entre o campo monocultor da sociologia e a biofísica. A base biofísica condiciona sem determinar de forma absoluta a condição humana em seus aspectos socioculturais.

\subsection{Policultura e conhecimento ambiental}

No estágio atual, marcado pela crise socioambiental, o conhecimento ambiental parece irromper como um campo policultor de saberes, à medida que se propõe a produzir e validar conhecimentos a partir das fronteiras dos campos monocultores ou disciplinares, que historicamente se constituíram separadamente. Trata-se de um campo que tende a minimizar o poder da monocultura de saberes, própria dos campos disciplinares, e a reivin- dicar uma policultura de saberes. Contudo, é oportuno ressaltar que a constituição do conhecimento ambiental como um campo policultor de saberes parece estar associada à (pre)disposição dos campos disciplinares (por intermédio dos novos sujeitos cognoscentes) de abrirem suas fronteiras, com vistas a incorporarem a problemática ambiental. Diferentemente dos campos disciplinares, que se constituíram se distanciando uns dos outros com vistas a acentuarem suas disjunções, o conhecimento ambiental investe em um movimento contrário, vez que seu processo de constituição depende da aproximação cada vez mais intensa entre os campos disciplinares. $\mathrm{Na}$ linha deste raciocínio, que se aproxima das formulações de Aímola (2002), a possibilidade de existência da "ciência ambiental" está associada à vontade de pesquisadores específicos alargarem as fronteiras de seus campos disciplinares de origem, tomando como referência a problemática ambiental (Souza-Lima, Silva \& Braga, 2013). Este processo de levar em conta a problemática ambiental pode ter ao menos dois significados. O primeiro é o do alargamento das fronteiras e o segundo é o da internalização da nova variável, historicamente excluída, sobretudo pelos campos disciplinares das humanidades e das sociedades. A rigor, trata-se de um movimento duplo, pois o processo de internalização da problemática ambiental pressupõe o alargamento das fronteiras dos campos disciplinares; e este alargamento, por sua vez, só se dá em função da problemática ambiental ter ficado de fora de determinados campos disciplinares. E os campos disciplinares associados às ciências biofísicas deixaram de fora as humanidades e as sociedades.

Neste sentido, não parece adequado caracterizar o "objeto" do campo de conhecimento ambiental como "propriedade" de qualquer um dos campos disciplinares envolvidos, pois cada campo tem o direito de reivindicar para si a forma genuína de reelaborar ou redefinir a problemática ambiental a partir de seus próprios cânones. Trata-se, portanto, de um "objeto" difuso, cuja principal característica é poder ser parte constitutiva de todos os campos disciplinares, sem ser propriedade de nenhum. Por não estar em lugar nenhum, o "objeto" do novo campo poderá estar em qualquer lugar, desde que vincule de forma complexa, como um tecido, conforme a sugestão de Morin (2003), os campos monocultores das sociedades/humanidades aos campos biofísicos. Em 
função desta singularidade de seu "objeto", o conhecimento ambiental começa a se constituir como um campo policultor de saberes, pois se apresenta (pre)disposto a cultivar seu "objeto" não de uma única perspectiva, mas de múltiplas formas.

\section{Considerações finais}

O propósito deste artigo foi iniciar uma reflexão, mas também identificar alguns elementos constitutivos e fundantes do novo campo que se propõe a produzir e validar conhecimento sobre o tema ambiental.

De maneira geral, um dos resultados concretos do artigo (Seção 2) é a identificação do reducionismo como fonte inspiradora dos campos disciplinares do conhecimento. O segundo achado da pesquisa, ainda associado ao fundamento epistêmico reducionista, é que este se projeta no contexto do debate socioambiental como um dos principais obstáculos a ser superado pelos processos de constituição do novo campo (Seção 3). O reducionismo é um obstáculo à medida que condiciona o sujeito cognoscente a se manter sempre próximo do núcleo duro de seu campo disciplinar. Note-se que o novo campo de conhecimento ambiental, ao contrário das demandas imperativas de um fundamento epistêmico reducionista, exige que o sujeito cognoscente afaste-se do núcleo duro e se dirija às fronteiras do seu campo disciplinar com vistas a dialogar com outros campos. Os contornos do novo campo de conhecimento constituem-se a partir não do núcleo duro de cada campo disciplinar, mas de suas fronteiras (Seção 3). O "objeto" deste novo campo, o "ambiental", não pode ser apreendido como propriedade

\section{Referências}

Abramovay, R. (Org.). Construindo a ciência ambiental. São Paulo: Annablume-Fapesp, 2002.

Aímola, L. Uma introdução à ciência ambiental: complexidade socioambiental, auto-organização e interdisciplinaridade. In: Abramovay, Ricardo (org.). Construindo a ciência ambiental. São Paulo: Annablume-Fapesp, 2002. p. 151-174.

Bachelard, G. O novo espírito científico. Rio de Janeiro: Tempo Brasileiro, 1974. de nenhum campo disciplinar, vez que se trata de um híbrido, resultado e resultante da coevolução dos campos disciplinares envolvidos na pesquisa (Seção 3).

O conceito de coevolução que irrompe como ideia-força, como fundamento epistêmico capaz de aproximar abordagens das teorias sociais e biofísicas por intermédio de práticas predispostas ao diálogo interdisciplinar, em si mesmo é insuficiente. Sem a vontade dos sujeitos cognoscentes e capazes de alterar as condições institucionais e objetivas, este fundamento tende a se tornar inócuo (Seção 3).

Neste sentido, os objetivos do artigo - a saber, identificar quais são os elementos fundantes do novo campo? E quais os obstáculos enfrentados pelo novo campo? - foram cumpridos de forma satisfatória. Nos limites deste artigo foi possível verificar que, a despeito do fundamento epistêmico reducionista projetar-se como um dos principais obstáculos, foi igualmente possível verificar que fundamentos menos ou não reducionistas irrompem como delineadores do conhecimento ambiental (Seções 2 e 3).

Contudo, pesquisas empírico-reflexivas, a serem realizadas a posteriori, poderão responder de forma menos imprecisa até que ponto os fundamentos epistêmicos, teóricos e metodológicos aqui elencados estão presentes de forma articulada em pesquisas envolvendo campos de conhecimento sociais e biofísicos. A explicitação destes limites do artigo é fundamental, pois a verificação em termos teórico-reflexivos em torno dos elementos supostamente fundantes do novo campo não garante em si mesma a fundação efetiva, muito menos o delineamento dos contornos do campo de conhecimento ambiental.

Bacon, F. Novum Organum. São Paulo: Nova Cultural, 1999. (Os Pensadores).

Bateson, G. Una unidad sagrada: pasos ulteriores hacia una ecología de la mente. Barcelona: Gedisa Editorial, 1993.

Beck, U. La sociedad del riesgo global. Madrid: Siglo XXI de España, 2006.

Bombassaro. L. C. As fronteiras da epistemologia: como se produz o conhecimento. Petrópolis: Vozes, 1992. 
Bourdieu, P. O poder simbólico. 9. ed. Rio de Janeiro: Bertrand Brasil, 2006.

Capra, F. A teia da vida: uma nova compreensão científica dos sistemas vivos. São Paulo: Cultrix, 1996.

As conexões ocultas: ciências para uma vida sustentável. São Paulo: Cultrix, 2002.

Castoriadis, C. Sujeito e verdade: no mundo social-histórico. Rio de Janeiro: Civilização Brasileira, 2007.

Cavalcanti, C. (Org.). Meio ambiente, desenvolvimento sustentável e políticas públicas. 2. ed. São Paulo: Cortez; Recife: Fundação Joaquim Nabuco, 1999.

Pensamento econômico, saber ecológico tradicional e regimes de troca fundados no altruísmo: nova perspectiva disciplinar para entender a sustentabilidade. 2002. Disponível em: <http://www.anppas.org.br/encontro_anual/encontro1/>. Acesso em 16/07/2008.

(Org.). Desenvolvimento e natureza: estudos para uma sociedade sustentável. 4. ed. São Paulo: Cortez; Recife: Fundação Joaquim Nabuco, 2003.

Cunha, C. L. N. et al. (Org.). Eutrofização em reservatórios: gestão preventiva. Estudo interdisciplinar na Bacia do Rio Verde, PR. v. 1. Curitiba: Editora UFPR, 2011.

Dawkins, R. O gene egoísta. São Paulo: Companhia das Letras, 2007.

Deléage, J. P. História da ecologia: uma ciência do homem e da natureza. Lisboa: Publicações Dom Quixote, 1993.

Descartes, R. Descartes: vida e obra. São Paulo: Nova Cultural, 1999. (Os Pensadores).

. As regras do método sociológico. 17. ed. São Paulo: Companhia Editora Nacional, 2002.

Durkheim, É. Coleção Grandes Cientistas Sociais. 4. ed. São Paulo: Ática, 1988.

Ferreira, L. C. A questão ambiental: sustentabilidade e políticas públicas no Brasil. São Paulo: Boitempo Editorial, 1998.

Floriani, D. A complexidade ambiental nos convida a dialogar com as incertezas da modernidade. Desenvolvimento e Meio Ambiente (UFPR), Curitiba, 4, 61-64, 2001.

Conhecimento, meio ambiente e globalização. Curitiba: Juruá, 2004a.

Disciplinaridade e construção interdisciplinar do saber ambiental. Desenvolvimento e Meio Ambiente (UFPR), Curitiba, 10, 33-38, 2004b.
. Ciências em trânsito, objetos complexos: práticas e discursos ambientais. Ambiente e Sociedade (Campinas), IX, 65-80, 2006.

Foladori, G. Limites do desenvolvimento sustentável. Campinas: Editora da UNICAMP; São Paulo: Imprensa Oficial, 2001.

; Tommasino, H. El concepto de desarrollo sustentable treinta años después. Revista Desenvolvimento e Meio Ambiente, 1, 41-56, 2000. Disponível em: <http://ojs.c3sl.ufpr. br/ojs2/index.php/made/article/view/3056/2447>. Acesso em: 09/10/2013.

Giddens, A. A política da mudança climática. Rio de Janeiro: Zahar, 2010.

Goldblatt, D. Teoria social e ambiente. Lisboa: Instituto Piaget, 1998.

Guha, R. El ecologismo de los pobres. Ecología política: cuadernos de debate internacional, Barcelona, 8, 137-153, 1994.

História da Filosofia. São Paulo:Abril Cultural, 1999.(Coleção Os Pensadores).

Japiassu, H. Interdisciplinaridade e patologia do saber. Rio de Janeiro: Imago, 1976.

Kant, I. Crítica da razão pura. São Paulo: Nova Cultural, 1999. (Coleção Os Pensadores).

Kelsen, H. Teoria pura do direito. 8. ed. São Paulo: WMF Martins Fontes, 2012.

Latour, B. Politicas da natureza: como fazer ciência na democracia. Bauru: EDUSC, 2004.

Leff, E. Epistemologia ambiental. São Paulo: Cortez, 2001a.

Saber ambiental: sustentabilidade, racionalidade, complexidade, poder. Petrópolis: Vozes, $2001 \mathrm{~b}$.

Racionalidade ambiental: a reapropriação social da natureza. Rio de Janeiro: Civilização Brasileira, 2006.

Ecologia, capital e cultura: a territorialização da racionalidade ambiental. Petrópolis: Vozes, 2009.

Leis, H. R. A modernidade (in)sustentável. Petrópolis: Vozes, 1999.

Mayr, E. Biologia, ciência única: reflexões sobre a autonomia de uma disciplina científica. São Paulo: Companhia das Letras, 2005.

Martínez-Alier, J. O ecologismo dos pobres. São Paulo: Contexto, 2011. 
Maturana, H. R.; Varela, F. J. A árvore do conhecimento: as bases biológicas da compreensão humana. São Paulo: Palas Athena, 2001.

Morin, E. Ciência com consciência. 7. ed. Rio de Janeiro: Bertrand Brasil, 2003.

.O método 1: a natureza da natureza. 2. ed. Porto Alegre: Sulina, 2005a.

. O método 3: o conhecimento do conhecimento. 3. ed. Porto Alegre: Sulina, 2005b.

. A religação dos saberes: o desafio do século XXI. 7. ed. Rio de Janeiro: Bertrand Brasil, 2010.

Norgaard, R. B. Development betrayed: the end of progress and a coevolutionary revisioning of the future. London and New York: Routledge, 1994.

Odum, E. P. Ecologia. Rio de Janeiro: Guanabara, 1983.

Pádua, J. A. (Org.). Ecologia e política no Brasil. Rio de Janeiro: Espaço e Tempo Brasileiro; IUPERJ, 1987.

Um sopro de destruição: pensamento político e crítica ambiental no Brasil escravista (1786-1888). Rio de Janeiro: Zahar, 2002.

Pepe, D. Um grupo de discussão aberta sobre a linguagem e a ciência: o Círculo Filosófico de Viena. In: De Masi, D. (Org.). A emoção e a regra: os grupos criativos na Europa de 1850 a 1950. 9. ed. Rio de Janeiro: José Olympio, 2007. p. 205-228.

Philipphi Jr., A.; Silva Neto, A. (Eds.). Interdisciplinaridade em ciência, tecnologia \& inovação. Barueri: Manole, 2011.

Platão. A república de Platão. São Paulo: Nova Cultural, 1999. (Os Pensadores).

Popper, K. R. Conjecturas e refutações: o desenvolvimento do conhecimento científico. Coimbra: Almedina, 2003.

Prigogine, Ilya. O fim das certezas: tempo, caos e as leis da natureza. São Paulo: Editora da Universidade Estadual Paulista, 1996.

; Stengers, I. A nova aliança: metamorfose da ciência. Brasília; Editora Universidade de Brasília, 1984.

Quivy, R.; Campenhoudt, L. V. Manual de investigação em Ciências Sociais. 5. ed. Lisboa: Gradiva, 2008. (Trajectos 17).

Ricklefs, R. E. A economia da natureza. Rio de Janeiro: Guanabara-Koogan, 1996.

Sachs, I. Rumo à ecossocioeconomia: teoria e prática do desenvolvimento. Organizado por Paulo Freire Vieira. São Paulo: Cortez, 2007.
Serres, M. O contrato natural. Rio de Janeiro: Nova Fronteira, 1991. $142 \mathrm{p}$.

O mal limpo: poluir para se apropriar? Rio de Janeiro: Bertrand Brasil, 2011. 110 p.

Sheldrake, R. O renascimento da natureza: o reflorescimento da ciência e de Deus. São Paulo: Cultrix, 1997.

Sete experimentos que podem mudar o mundo: pode a ciência explicar o inexplicável? São Paulo: Cultrix, 2001.

Silva, R. O. et al. As vozes da floresta e a ecologia dos saberes. In: Steenbock, Walter et al. (Org.). Agrofloresta, ecologia e sociedade. Curitiba: Kairós, 2013. p. 39-60.

Sobral, M. C.; Lima, J. E.; Philippi Jr., A. Construção da interdisciplinaridade na pós-graduação em ciências ambientais. In : Philipphi Jr., A.; Silva Neto, A. (Eds.). Interdisciplinaridade em ciência, tecnologia \& inovação. Barueri: Manole, 2011.

Sousa Santos, B.; Meneses, M. P. G.; Nunes, J. A. Introdução: Para ampliar o cânone da ciência: a diversidade epistemológica do mundo. In: Sousa Santos, B. (Org.). Semear outras soluções: os caminhos da biodiversidade e dos conhecimentos rivais. Rio de Janeiro: Civilização Brasileira, 2005.

Souza-Lima, J. E.; Knechtel, M. R. Multiculturalismo e educação ambiental: dois campos de coexistência das racionalidades culturais e ambientais. In: Morales, Angélica Góis et al. (Org.). Educação ambiental e multiculturalismo. Ponta Grossa: Editora UEPG, 2012. p. 27-36.

; Chiaramonti, C.; Maciel-Lima, S. M. Prácticas agroecológicas, sustentabilidad y política pública: limitaciones y potencialidades de una cooperativa. Cayapa. Revista Venezolana de Economía Social, Universidad de los Andes Venezuela 11(22), 103-123, julio-diciembre, 2011.

; Silva, R. M.; Braga, P. C. A agrofloresta e os contornos de um sujeito (re)significado. Cad. de Pesq. Interdisc. em Ciências Humanas, Florianópolis, 14(104), 25-46, jan./jun. 2013. Disponível em: <https://periodicos.ufsc.br/index.php/ cadernosdepesquisa/article/view/1984-8951.2013v14n104p25/ pdf $>$. Acesso em 09/10/2013.

Stengers, I. A invenção das ciências modernas. São Paulo: Editora 34, 2002.

Para além da grande separação, tornamo-nos civiliza-

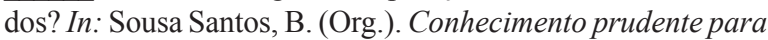
uma vida decente: um discurso sobre as ciências revisitado. São Paulo: Cortez, 2004. p. 131-149.

Touraine, A. Um novo paradigma: para compreender o mundo de hoje. Petrópolis: Vozes, 2006. 
Vieira, P. F.; Weber, J. (Orgs.). Gestão de recursos naturais renováveis e desenvolvimento: novos desafios para a pesquisa ambiental. 3. ed. São Paulo: Cortez, 2002.
Weber, M. Sobre a teoria das ciências sociais. 2. ed. Lisboa: Editorial Presença, 1977.

Wittgenstein, L. Investigações filosóficas. São Paulo: Nova Cultural, 1999. (Os Pensadores). 